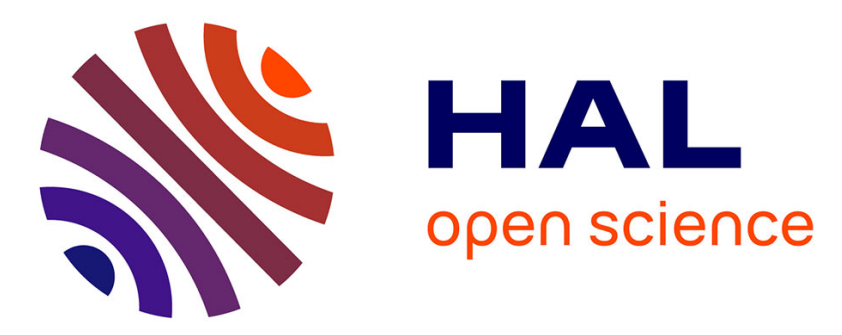

\title{
Hierarchical porous nitrogen-doped carbon beads derived from biosourced chitosan polymer
}

Camelia Matei Ghimbeu, Valeriy Luchnikov

\section{To cite this version:}

Camelia Matei Ghimbeu, Valeriy Luchnikov. Hierarchical porous nitrogen-doped carbon beads derived from biosourced chitosan polymer. Microporous and Mesoporous Materials, 2018, 263, pp.42-52. 10.1016/j.micromeso.2017.12.001 . hal-02465009

\section{HAL Id: hal-02465009 \\ https://hal.science/hal-02465009}

Submitted on 7 Feb 2020

HAL is a multi-disciplinary open access archive for the deposit and dissemination of scientific research documents, whether they are published or not. The documents may come from teaching and research institutions in France or abroad, or from public or private research centers.
L'archive ouverte pluridisciplinaire HAL, est destinée au dépôt et à la diffusion de documents scientifiques de niveau recherche, publiés ou non, émanant des établissements d'enseignement et de recherche français ou étrangers, des laboratoires publics ou privés. 


\section{Hierarchical Porous Nitrogen-doped Carbon Beads Derived From Biosourced Chitosan Polymer}

Camélia Matei Ghimbeu*, and Valeriy A. Luchnikov ${ }^{*}$

Université de Strasbourg, Université de Haute-Alsace, Institut de Science des Matériaux de Mulhouse, UMR 7361 CNRS-UHA, 15 rue Jean Starcky, 68057 Mulhouse-France.

* Corresponding authors:

C. Matei Ghimbeu: Tel.: +33 389608743;

E-mail address: camelia.ghimbeu@uha.fr 


\begin{abstract}
Carbon microbeads with diameters of a few hundreds of microns are produced by dropping chitosan acetate (CA) solution in liquid nitrogen, freeze drying and thermal treatment in inert atmosphere at $700^{\circ} \mathrm{C}$. The structure of the beads is characterized by hierarchical porosity at the three length scales: (i) macropores originating from the phase separation during the water ice crystal grow inside the droplets, immersed in liquid nitrogen, (ii) arising in course of the beads thermal treatment, leading to the removal of the porogen molecules (Pluronic F127) added to the CA solution and (iii) micropores induced by the carbonization of chitosan resin. The carbon beads have a rigid skin which present wrinkles with well-defined structure.

The carbon bead pore size and volume could be tuned by varying the type and amount of cross-linkers (glyoxal and glyoxylic acid) and template. This was related to the chitosan ability to cross-link in a different manner with the cross-linkers as showed by ${ }^{13} \mathrm{C}$ NMR resulting in chitosan resin able to self-assemble with Pluronic F-127 template through $\mathrm{H}$ bonding interactions. The beads are produced by a green process employing entirely biosourced and renewable materials that make them attractive for the large scale applications requiring nanoporous carbons.
\end{abstract}

KEY WORDS: Chitosan Acetate; Porous carbon; Polymers; Hierarchical porosity;

Biosources; 


\section{Introduction}

Chitosan, a natural random linear copolymer of $\beta$-(1-4)-linked D-glucosamine and N-acetylD-glucosamine, has attracted lately great attention as a biosource to obtain carbonized materials for multiple applications. Recently, single layer $\mathrm{N}$-doped graphene was synthesized by pyrolysis of thin chitosan films under argon at $800{ }^{\circ} \mathrm{C}$ [1]. Chitosan based activated alumina-carbon composite beads were explored for immobilization of carbonic anhydrase for fixation of anthropogenic $\mathrm{CO}_{2}$ into calcium carbonate [2]. Microporous carbons prepared from chitosan precursor by carbonization followed by activation were shown to be excellent materials as well for hydrogen and $\mathrm{CO}_{2}$ storage $[3 ; 4]$, electrodes for supercapacitor [5-8] or battery applications [9;10]. Composites based on graphene, graphene oxide or carbon nanotubes (CNTs) and chitosan derived carbon have been reported as well $[6 ; 7 ; 11 ; 12]$.

The main factors which make chitosan so attractive for the above-mentioned applications are related to (i) its availability as the sub-product of food industry [13;14], (ii) the high carbon yield after carbonization ( $50 \mathrm{wt} . \%)$ and (iii) the presence of the amine group in its structure, that results in the nitrogen self-doping of the derived carbon materials improving the electronic structure and the wettabillity. Particularly, the $\mathrm{N}$-doped carbon materials were extensively studied recently as efficient "metal-free catalyst" electrocatalysts [15] for the oxygen reduction reaction (ORR) $[16 ; 17]$ in the aim of replacing the expensive Pt catalyst in such reactions. On the other hand, the carbons with high content of nitrogen allow to enhance the electrochemical capacity in supercapacitors because of the shift of the Fermi level to the valence band in carbon electrode, improving the electronic conductivity and facilitating the electron transfer [18].

However, carbonized materials should be optimized in order to provide simultaneously high specific surface, optimal pore size distribution, good transport properties and facile manipulation. 
In this aim, carbon beads are of great interest since they are easy to handle and to recover from reaction medium in practical applications. Their synthesis in the absence of binders and with controlled porosity at different scales is still very challenging. Carbon beads possessing hierarchical porosity combining macropores (> $50 \mathrm{~nm})$, mesopores $(2-50 \mathrm{~nm})$ and micropores $(<2 \mathrm{~nm})$ present several advantages with respect to the single-sized porous materials [19]. The large macropores enhance permeability and ion diffusion while the mesopores allow for low resistance pathways through the material. The smaller pores (micropores and mesopores) increase the specific surface area and the porous volume, improving the gas/liquid adsorption capacity or providing high capacitance for supercapacitors through electric double layer formation [20-24].

Several approaches were used to synthesize carbon beads including CVD (chemical vapor deposition), hard-template, and emulsion/suspension polymerization [25-31]. Although, chitosan beads may be obtained by various methods as reviewed [32;33], no reports on chitosan derived carbon beads are reported to our knowledge.

Direct carbonization of biosourced polymers is sustainable, convenient and cost effective method to prepare carbons but is such cases the derived carbon materials are characterized by limited porosity. Activation is the most employed and widely used approach to obtain carbon materials with well-developed porosity by using activation agents, such as $\mathrm{KOH}, \mathrm{K}_{2} \mathrm{CO}_{2}$ or $\mathrm{CO}_{2}[3 ; 5 ; 9]$. However, the corrosive nature of the employed activating agents, the low carbon yield and wide pore size distribution are the main limitations for this method.

The template approaches become alternative and versatile for fabricating porous carbon with controlled pore sizes and architectures [34-37].

The salt-template route involving the mixture of a carbon source with a metallic salt and simultaneous thermal annealing at high temperatures [38-40] was proposed as an alternative to activation method for the preparation of micro/mesoporous materials. The advantage of 
such method lies in the use of cheap salts easily recovered in the end of the synthesis by simple washing with water, but also the high yield of obtained carbon compared with activation routs is an advantage. Deng et al. [8] used such approach to increase the porosity of chitosan.

The hard-templating involving the use of a silica or zeolite template which is infiltrated with a polymer or other carbon source followed by the removal of the template was proposed also for chitosan based carbons [41;42]. The large size and limited solubility of biomass-based molecules combined with hard templates having confined pore sizes may induce steric effects and limitation of polymer impregnation into the template pores/channels. In addition, the complex process, dangerous reagents used to remove the template (HF) and high cost hinders their large scale practical use. As an alternative, the soft-template method was proposed as a convenient and flexible approach to obtain carbon materials with various pore structures [34;36;43]. Thermosetting phenolic resins are self-assembled with a copolymer template via hydrogen or covalent bonding, followed by a thermal treatment generating the formation of a micro/mesoporous carbon. Phenol-formaldehyde resins are the most employed [36] due to their high thermal stability and high carbon yield. The carcinogen nature of formaldehyde brings researchers to look for more environmentally friendly substitutes. Glyoxal presenting two aldehyde groups was proposed in this aim [44;45] and more recently we have proposed a biosourced derived aldehyde, i.e., glyoxylic acid which have double functionality i.e., aldehyde and carboxylic acid playing a role of cross-linker and catalyst in the synthesis of resin [46]. As for the carbon source, resorcinol or phloroglucinol was used as an alternative instead of phenol which is highly toxic. However, chitosan was never combined with such green cross-linker in the presence of organic amphiphilic templates to obtain hierarchical porous carbons.

In this paper we propose a green and simple soft-template approach to design N-doped 
hierarchical carbon beads derived from biosourced chitosan acetate and green cross-linkers. The resulting materials present hierarchical porosity and are characterized by moderate BET surface area and tuned pore sizes depending on the amount of template or cross-linker used. The structure of chitosan polymer materials and their mechanism of transformation into carbon were studied by ${ }^{13} \mathrm{C}$ NMR and TGA analysis and discussed herein.

\section{Experimental}

\subsection{Material Synthesis}

A solution of 1 wt.\% chitosan (Sigma-Aldrich, 448877-50g, lot \#MKBJ9698V, acetylation degree $20 \%$ ) was prepared using aqueous solution of acetic acid (1\% wt.) as solvent. In this solution a triblock copolymer template (Pluronic F127, Aldrich) was dissolved under stirring at $\sim 30^{\circ} \mathrm{C}$, followed by addition at room temperature of an aqueous solution of glyoxal (40 wt.\%, Aldrich) or glyoxylic acid. Several materials were prepared according to the details provided in Table 1. For comparison purpose, one reference sample (CB-R) was prepared only with chitosan (no template and no cross-linker).

Table 1: Synthesis conditions used for the preparation of carbon beads.

\begin{tabular}{ccccc}
\hline Carbon beads & Chitosan, & Pluronic & Glyoxal, & Glyoxylic Acid, \\
& ml & F127, g & ml & g \\
\hline CB-R & 90 & - & - & - \\
CB-A & 90 & 1.8 & - & - \\
CB-B & 90 & 1.8 & 0.9 & - \\
CB-C & 90 & 1.8 & 1.8 & - \\
CB-D & 90 & 0.9 & 0.9 & - \\
CB-E & 90 & 1.8 & - & 0.7 \\
\hline
\end{tabular}


The as-obtained solution was dropped (with the rate of 1 droplet per second, approximately) into a vessel filled by liquid nitrogen. The frozen beads were freeze-dried in a Labologic FD$1 \mathrm{C}$ setup, and then carbonized at $700^{\circ} \mathrm{C}$ for 1 hour, with a heating rate of $2 \mathrm{~K} / \mathrm{min}$ in $\mathrm{Ar}$ atmosphere, as schematically illustrated in Figure 1. The annealing temperature was investigated on CB-B sample and two supplementary temperatures were used, i.e., $500^{\circ} \mathrm{C}$ and $900^{\circ} \mathrm{C}$, respectively.

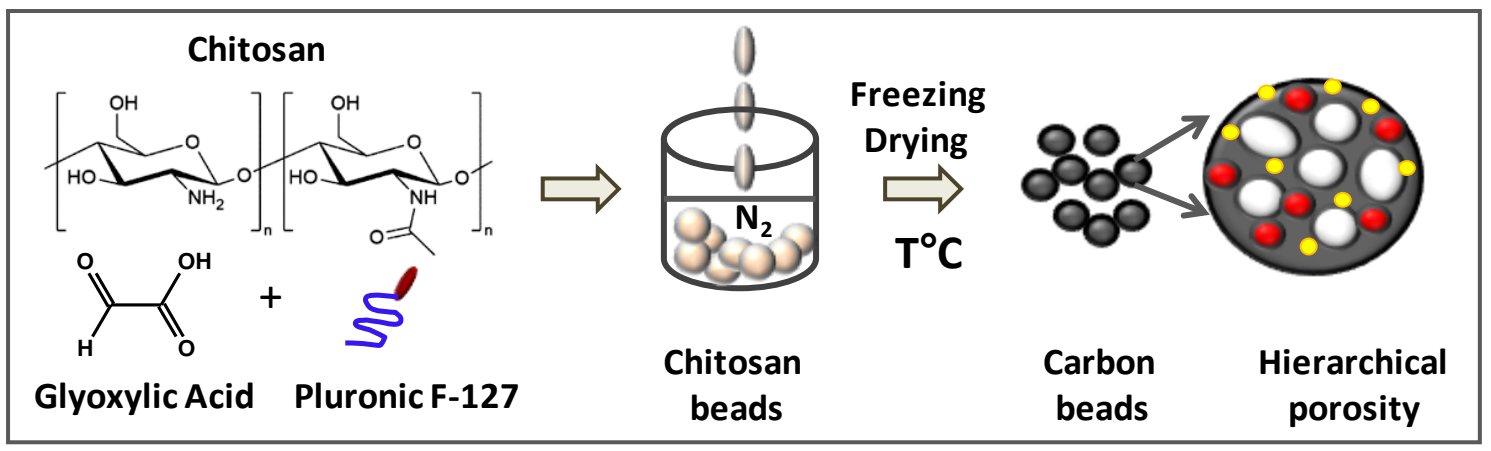

Figure 1: Schematic representation of the synthesis process of hierarchical N-doped carbon beads.

\subsection{Material Characterization}

The porosity of the carbons was analyzed by nitrogen and $\mathrm{CO}_{2}$ adsorption at $77 \mathrm{~K}$ and $273 \mathrm{~K}$, respectively, using a Micromeritics ASAP 2420 instrument. Before analysis, the materials were degassed in vacuum at $473 \mathrm{~K}$ (heating rate of $10 \mathrm{~K} / \mathrm{min}$ ) for $12 \mathrm{~h}$. The BET specific surface area (SSA) was calculated from the nitrogen linear plot in the relative pressure range of 0.01-0.05. The micropore volume $\left(\mathrm{V}_{\text {micro }}\right)$ was calculated with the Dubinin-Radushkevich (DR) equation in the relative pressure interval, $\mathrm{P} / \mathrm{P}_{0}, 10^{-4}$ to $10^{-2}$. The total pore volume (Vt) was determined from the amount of nitrogen adsorbed at a relative pressure of 0.99 , while the mesoporous volume (Vmeso) was obtained by substracting the Vmicro from Vt. The pore size distributions (PSD) was determined from the adsorption branch of nitrogen and $\mathrm{CO}_{2}$ isotherms using the non local density function theory (NLDFT) model developed for carbon 
slit pores.

The porosity of carbon material was further analyzed by mercury intrusion porosimetry (Micromeritics, Autopore IV). This apparatus allows measuring pressures between $2.6 \times 10^{-6}$ and $200 \mathrm{MPa}$. Prior to measurements samples were outgassed at $25^{\circ} \mathrm{C}$ under primary vacuum for about 1 hour. A certain amount of degassed carbon $(\sim 40 \mathrm{mg})$ were introduced in the penetrometer, which was further inserted in the low pressure chamber $\left(2.6 \times 10^{-6}-0.2 \mathrm{MPa}\right)$. During this first stage, the cell was vacuumed and then filled by mercury. The penetrometer containing the sample and the mercury was then placed in the high pressure chamber $(0.2$ $200 \mathrm{MPa}$ ). During this second stage, a pressure was applied to force mercury diffusion into porous sample. As intrusion occurs, the mercury level in the stem varies. Washburn equation was used to determine the pore size [47]:

$$
\mathrm{D}=-4 \sigma \cos \theta / \mathrm{P}
$$

Where $\mathrm{P}$ is the applied pressure $(\mathrm{Pa}), \mathrm{D}$ is the diameter of the pore $(\mathrm{m}), \sigma$ is the interfacial tension $\left(\mathrm{N} \cdot \mathrm{m}^{-1}\right)$ and $\theta$ the contact angle $\left(^{\circ}\right)\left(\right.$ for mercury $\sigma=485 \mathrm{mN} \cdot \mathrm{m}^{-1}$ and $\theta=130^{\circ}$ ).

SEM images of the materials at different length scales were obtained at the PHILIPS - FEI (XL-30 FEG) platform while the TEM images were obtained at the JEOL ARM200 set-up.

X-ray photoelectron spectroscopy (XPS) was performed with a VG Scienta SES 200-2 spectrometer equipped with a monochromatized Al Ka X-ray source $(1486.6 \mathrm{eV})$ and a hemispherical analyzer. Wide scan and high resolution (C1s, N1s and O1s) XPS spectra are recorded respectively with a pass energy of $500 \mathrm{eV}$ and $100 \mathrm{eV}$. The analysed surface area was approximately $3 \mathrm{~mm}^{2}$ and the pressure in the analysis chamber during experimentation was about $10^{-9}$ mbar. Spectra were subjected to a Shirley baseline and peak fitting was made with mixed Gaussian-Lorentzian components with equal full-width-at-half-maximum (FWHM) using CASAXPS version 2.3.17software. All the binding energies (BE) are referenced to the $\mathrm{C} 1 \mathrm{~s}$ peak ( $\mathrm{sp}^{2}$ carbon atoms) from the "graphitic material" at $284.6 \mathrm{eV}$ and 
given with a precision of $0.1 \mathrm{eV}$.

The chitosan structure was studied by solid-state ${ }^{13} \mathrm{C}$ magic angle spinning (MAS) NMR. The NMR spectra were obtained at a frequency of $100.6 \mathrm{MHz}, 400.13 \mathrm{MHz}$ respectively on a Bruker Avance 400 NMR spectrometer. Samples were packed in $4 \mathrm{~mm}$ diameter cylindrical zirconia rotors with Kel-F rotor end caps and spun at the "magic angle" at $12 \mathrm{kHz}$ in a Bruker DB MAS probe [40;46]. Cross-polarization (CP) spectra were acquired using a $90^{\circ} 1 \mathrm{H}$ pulse of $3.7 \mu \mathrm{s}$ duration, a $1 \mathrm{~ms}$ contact time and a $5 \mathrm{~s}$ recycle delay. Free induction decays were acquired with a sweep width of $85 \mathrm{kHz}$. $8 \mathrm{~K}$ data points were collected over an acquisition time of $48 \mathrm{~ms}$.

The thermal decomposition behavior of chitosan derived materials during the heating under inert atmosphere was monitored between room temperature and $600^{\circ} \mathrm{C}$ with a TGA (METTLER-TOLEDO TGA 851e) set-up. A slow heating rate similar to that used for the carbonization of the chitosan beads was used $\left(2^{\circ} \mathrm{C} / \mathrm{min}\right)$.

\section{Results and discussion}

\subsection{Textural properties}

Firstly, the influence of thermal annealing temperature on the textural properties of carbon beads were evaluated at $500^{\circ} \mathrm{C}, 700^{\circ} \mathrm{C}$ and $900^{\circ} \mathrm{C}$ and the nitrogen adsorption/desorption isotherms are shown in Figure S1 (Supporting Information's). All three materials are characterized by similar IV type isotherm (IUPAC classifications) presenting H1 hysteresis loop indicating condensation in the mesopores. The hysteresis is rather similar for all materials and translates into comparable mesoporous volumes, ranged between 0.31 and 0.35 $\mathrm{cm}^{3} \cdot \mathrm{g}^{-1}$ (Table S1, Supporting Information's).

In addition, an increase in the nitrogen adsorption at low pressures $\left(\mathrm{P} / \mathrm{P}_{0}<0.1\right)$ is noticed suggesting the presence of micropores. For the materials heat treated at $500^{\circ} \mathrm{C}$ and $700^{\circ} \mathrm{C}$, the microporous volume is similar $\left(0.14\right.$ and $\left.0.16 \mathrm{~cm}^{3} \cdot \mathrm{g}^{-1}\right)$, slightly higher for CB-B $700^{\circ} \mathrm{C}$, while 
for $900^{\circ} \mathrm{C}$ the microporous volume is much lower, i.e., $0.10 \mathrm{~cm}^{3} \cdot \mathrm{g}^{-1}$.

The SSA varies in the same order as well, increases between 500 and $700^{\circ} \mathrm{C}$ from 397 to 433 due to carbonization of phenolic resin with the release of $\mathrm{CO}_{\mathrm{x}}$ and $\mathrm{H}_{2}$ gaseous species. When further increases the temperature to $900^{\circ} \mathrm{C}$ the SSA decreases $\left(203 \mathrm{~m}^{2} \cdot \mathrm{g}^{-1}\right.$, Table S1), due to the porosity closure. The same trend of SSA evolution with the temperature was observed previously on phenolic resins based on phloroglucinol [48]. Therefore, the $700^{\circ} \mathrm{C}$ was selected as optimal temperature which ensures carbonization of the precursors and developed microporosity.

The nitrogen adsorption/desorption isotherms of the carbon materials prepared under different experimental conditions are shown in Figure 2. The influence of the amount cross-linker agent (glyoxal) on the textural properties was as well investigated. The quantity was increased gradually from $0.0 \mathrm{ml}(\mathrm{CB}-\mathrm{A})$ to $0.9 \mathrm{ml}(\mathrm{CB}-\mathrm{B})$ and $1.8 \mathrm{ml}(\mathrm{CB}-\mathrm{C})$, respectively.

For low quantities of glyoxal (CB-A and CB-B), the isotherms present an increase of $\mathrm{N}_{2}$ adsorption quantity at low pressure, suggesting the formation of micropores, in addition to mesopores. On the contrary, a high quantity of glyoxal (CB-C) does not allow anymore the formation of micropores. In consequence, the specific surface area of CB-A and CB-B (337 and $\left.433 \mathrm{~m}^{2} \cdot \mathrm{g}^{-1}\right)$ are significantly much higher than for CB-C $\left(90 \mathrm{~m}^{2} \cdot \mathrm{g}^{-1}\right)$. The porous volume has the same evolution as the SSA (see Table 2).

It is important to mention that the mesoporous volume is 2 or 3 times higher than the microporous volume (Table 2). The DFT pore size distribution depicted in Figure 2b, show uniform mesopore size distribution for all 3 materials with sizes centered around $15 \mathrm{~nm}$. Hence, the glyoxal do not have an influence on the mesopore size but rather on their quantity. In addition, the presence of micropores (pores $<2 \mathrm{~nm}$ ) is also seen, therefore, a double pore size distribution coexists in the materials.

If the textural properties are compared with those of the reference carbon beads (CB-R) made 
only with chitosan (Figure S2, Supporting Information's), it can be seen that the CB-R material is purely microporous (type I nitrogen adsorption/desorption isotherm). The pore size distribution confirms as well the existence of micropores with size $<1.0 \mathrm{~nm}$ and the absence of mesopores. The specific surface area is $350 \mathrm{~m}^{2} \cdot \mathrm{g}^{-1}$, therefore, comparable with the other $\mathrm{CB}$, while the total porous volume is $0.19 \mathrm{~cm}^{3} \cdot \mathrm{g}^{-1}$, which is much lower than the beads prepared in the presence of the template (Table 2). The results suggest that the template have no influence on the microporosity formation but rather to create the mesopores. This founding is in agreement with our previous works [40].

Table 2: Textural properties of carbon beads synthesized in different conditions as determined using $\mathrm{N}_{2} / \mathrm{CO}_{2}$ adsorption and $\mathrm{Hg}$ intrusion isotherms and chemical composition obtained by XPS.

\begin{tabular}{|c|c|c|c|c|c|c|c|c|c|}
\hline $\begin{array}{c}\text { Carbon } \\
\text { beads }\end{array}$ & $\begin{array}{l}\mathbf{S S A}^{\mathbf{a}} \\
\mathrm{m}^{2} \cdot \mathbf{g}^{-1}\end{array}$ & $\begin{array}{c}\mathrm{Vt}^{\mathrm{a}} \\
\mathrm{cm}^{3} \cdot \mathrm{g}^{-1}\end{array}$ & $\begin{array}{c}\mathrm{Vt}^{\mathbf{b}} \\
\mathrm{cm}^{3} \cdot \mathrm{g}^{-1}\end{array}$ & $\begin{array}{c}V_{\text {micro }}{ }^{a} \\
\mathrm{~cm}^{3} \cdot \mathrm{g}^{-1}\end{array}$ & $\begin{array}{l}V_{\text {micro }}{ }^{c} \\
\mathrm{~cm}^{3} \cdot \mathrm{g}^{-1}\end{array}$ & $\begin{array}{c}V_{\text {meso }^{a}} \\
\mathrm{~cm}^{3} \cdot \mathrm{g}^{-1}\end{array}$ & $\begin{array}{c}\mathrm{C} \\
\text { at.\% }\end{array}$ & $\begin{array}{c}\text { O } \\
\text { at. } \%\end{array}$ & $\begin{array}{c}\mathrm{N} \\
\text { at. } \%\end{array}$ \\
\hline CB-A & 337 & 0.51 & 4.5 & 0.13 & 0.13 & 0.38 & 90.2 & 3.4 & 6.4 \\
\hline CB-B & 433 & 0.51 & 2.5 & 0.16 & 0.13 & 0.35 & 91.0 & 4.2 & 4.8 \\
\hline CB-C & 90 & 0.17 & 2.2 & 0.05 & 0.11 & 0.12 & 93.8 & 2.8 & 3.4 \\
\hline CB-D & 354 & 0.26 & 12.0 & 0.15 & 0.15 & 0.11 & 91.2 & 3.5 & 5.3 \\
\hline CB-E & 357 & 0.63 & 15.5 & 0.14 & 0.14 & 0.49 & 91.2 & 3.5 & 5.3 \\
\hline
\end{tabular}

a- Calculated from nitrogen adsorption isotherms; b-calculated from $\mathrm{Hg}$ intrusion isotherms and c-calculated from $\mathrm{CO}_{2}$ adsorption isotherms. 

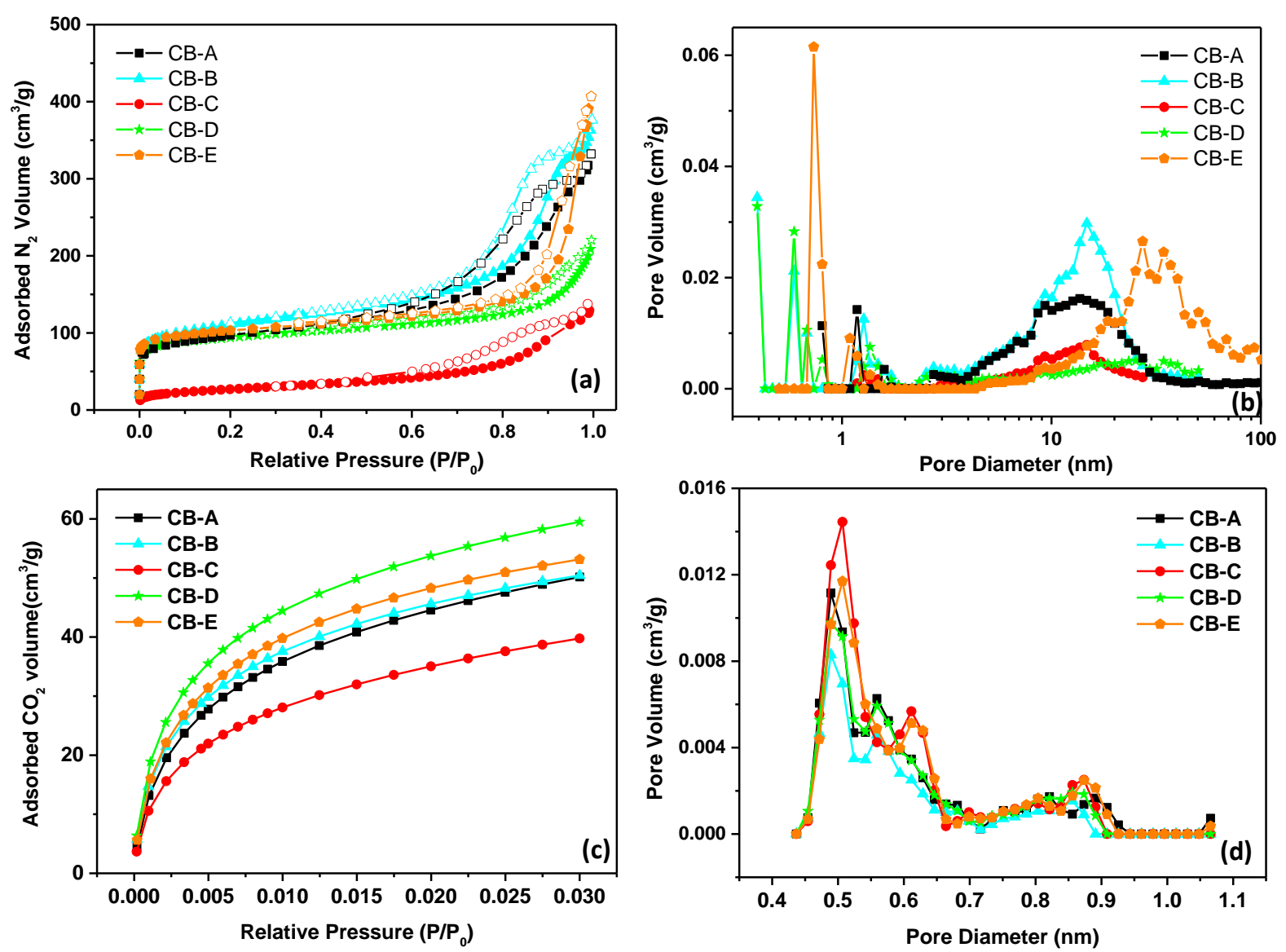

Figure 2: (a) Nitrogen adsorption/desorption isotherms and (b) $\mathrm{N}_{2}$ NLDFT pore size distribution (c) $\mathrm{CO}_{2}$ adsorption isotherms (d) $\mathrm{CO}_{2}$ NLDFT pore size distribution of carbon beads synthesized in different conditions (full symbols-adsorption; empty symbolsdesorption).

Considering that the lower quantities of glyoxal provided higher surface area materials carbons and uniform pore size, the CB-B conditions were used kept as reference to study the influence of template quantity. When the quantity of template is diminished by half $(0.9 \mathrm{~g}$ for CB-D compared to $1.8 \mathrm{~g}$ for $\mathrm{CB}-\mathrm{B})$, we can observe that the low pressure isotherm curve $\left(\mathrm{P} / \mathrm{P}_{0}<0.1\right)$ is kept unchanged while the hysteresis corresponding to the mesopores is significant reduced. This is in the line with the constant micropore volume $\left(\sim 0.15 \mathrm{~cm}^{3} \cdot \mathrm{g}^{-1}\right)$ and the decrease of mesopore volume (from 0.35 to $0.11 \mathrm{~cm}^{3} \cdot \mathrm{g}^{-1}$, Table 2). The mesopore size 
distribution become broader also not very well defined (Figure 2b). Therefore, the template strongly influences the mesopore size/distribution and amount.

The last investigated parameter was the type of cross-linker. The glyoxal used for the synthesis of CB-B was replaced by glyoxylic acid (CB-E). This has no impact on the micropores but rather on the mesopore size and quantity. The mesopore size increases from 15 $\mathrm{nm}$ for CB-B to $30 \mathrm{~nm}$ for $\mathrm{CB}-\mathrm{E}$ as well as the mesopore volume from 0.35 to $0.49 \mathrm{~cm}^{3} \cdot \mathrm{g}^{1}$, respectively. The macroporosity of the samples was assessed by mercury intrusion/extrusion isotherms and the obtained isotherms are shown in Figure 3a. The CB-A, CB-B and CB-C present rather similar pore volumes, ranged between 2.2 and $4.5 \mathrm{~cm}^{3} \cdot \mathrm{g}^{1}$ (Table 2) while the CB-D and CB-E are characterized by significantly higher porous volume (12.0 to 15.5 $\mathrm{cm}^{3} \cdot \mathrm{g}^{1}$ ). For all samples the porous volume determined by $\mathrm{Hg}$ intrusion is larger than the one obtained by nitrogen adsorption suggesting the presence of plenty macropores. The pore size distribution (Figure 3b) show well defined peaks in the mesopore region $(<50 \mathrm{~nm})$ with size in well agreement with the size obtained by nitrogen adsorption (Figure 2b). A zoom in the macropore region (in-set Figure 3b) allow to observe a broad pore size distribution, with pore size comprised between $100 \mathrm{~nm}$ and several micrometers.
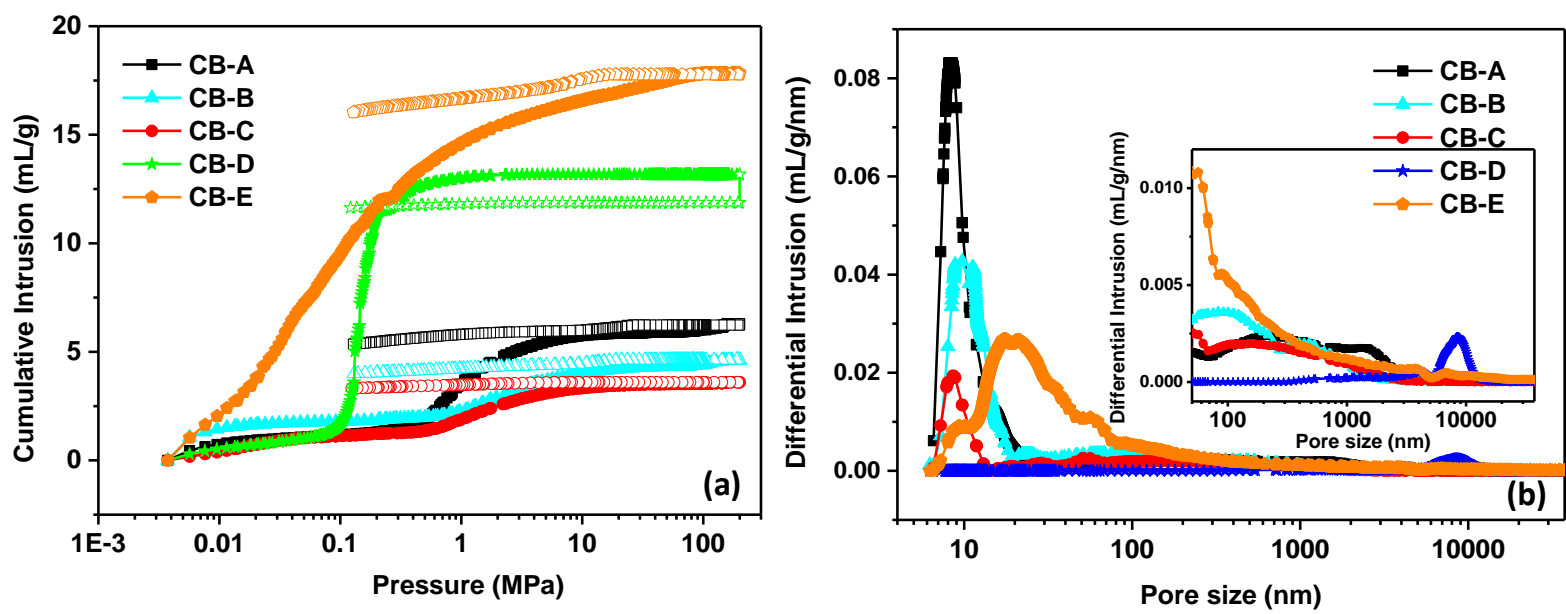

Figure 3: Hg intrusion/extrusion isotherms (a) and pore size distribution (in-set: zoom on the macropore zone $(>50 \mathrm{~nm})(\mathrm{b}$ 


\subsection{Beads morphology}

The carbon beads were prepared by thermal treatment of chitosan modified beads obtained by freeze-dry method. The chitosan beads are of white color and present uniform spherical shape as seen in Figure 4a. After the thermal treatment we noticed that the shape of the beads is maintained while shrinkage in the size takes place (Figure $4 \mathrm{c}$, d) due to the polymer degradation during the carbonization treatment. The polymer bead size is around $2.5 \mathrm{~mm}$ and after carbonization it decreases to $\sim 1.1 \mathrm{~mm}$, therefore, a shrinking of $75 \%$ occurs during the thermal annealing process.
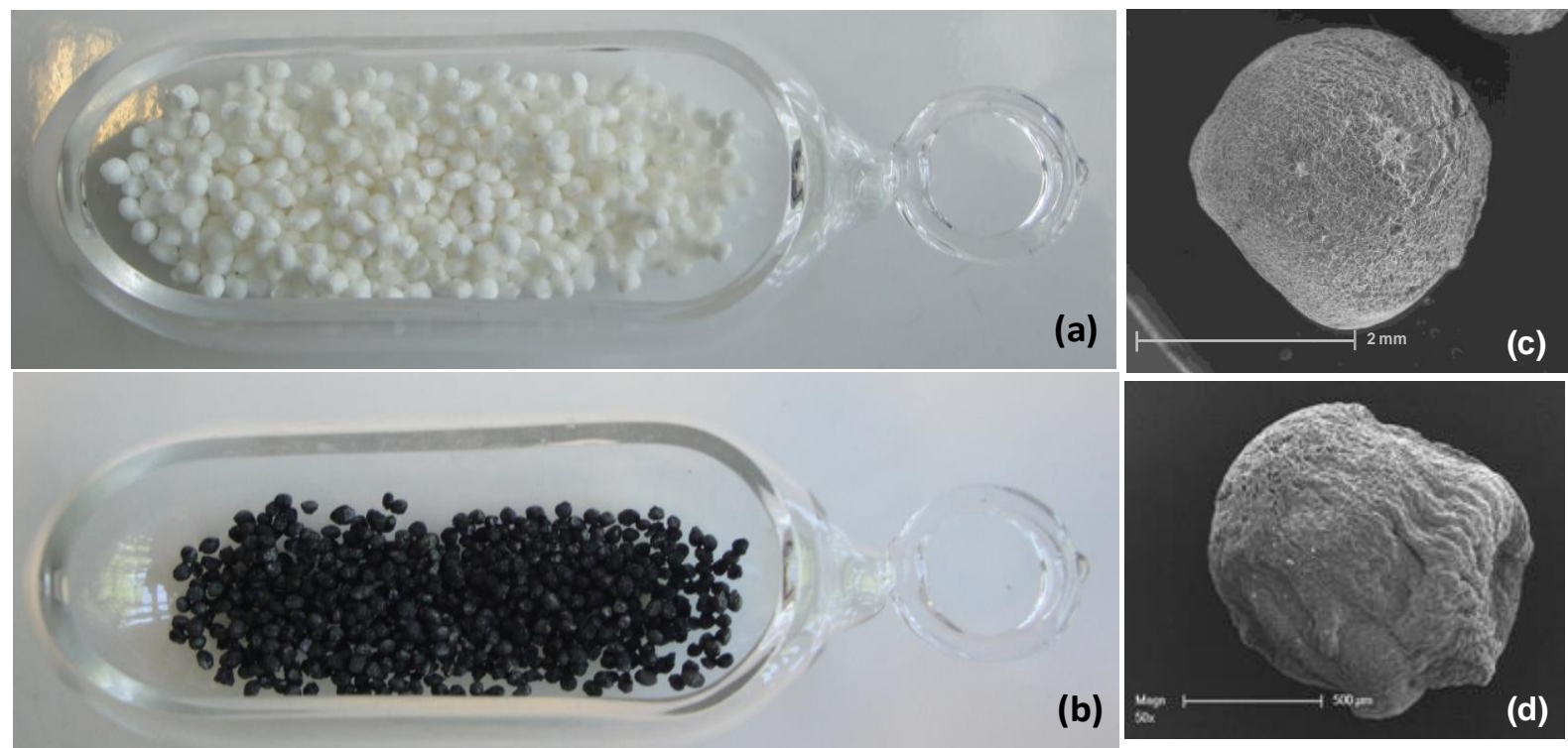

Figure 4: Photos of chitosan beads (a) before and (b) after thermal carbonization treatment and their corresponding SEM images (c, d). 


\subsubsection{Beads interior morphology}

A closer inspection of these materials on BC-B sample by SEM is done. We observe in Figure 5 that the size of the beads is around $0.5-1.0 \mathrm{~mm}$, with almost spherical shape (Fig. 5a). A few beads were crashed and their interior was visualized at several length scales (Fig. 5b-d). The beads have highly porous structure, with the pore diameters comprised between 5 and $20 \mu \mathrm{m}$, approximately (Fig. 5b). This macroporosity maybe related to water ice microcrystal's growth and phase separation during the chitosan solution droplets freezing in liquid nitrogen, and it is present both in the freeze-dried beads both before (Figure S3, Supporting Information) and after the carbonization step (Figure 5). The reference carbon bead (CB-R) presents as well a macroporosity while the morphology is characterized by much thinner and well oriented carbon shits (Figure S4, Supporting Informations). The formation of the macropores in the freeze-dried water solutions of biopolymers is well known in regenerative medicine and tissue engineering, where this process is used for the scaffolds design [49-52].

It is known that the morphology of the pores is dependent on the freezing conditions; thus, Stokolus and Tuszynski obtained highly oriented pores in the aragose via a uniaxial temperature gradient by exposing one of the ends of a glass tube filled by aragose solution to a block of dry ice cooled by liquid nitrogen [51]. In our experiments, we notice orientation effects of the macropores only in the case of reference carbon beads made in the absence of template/cross-linker (Figure S4, Supporting Information's). Even if the reason is not well understood, it seems that the chitosan solution composition affects such orientation. 

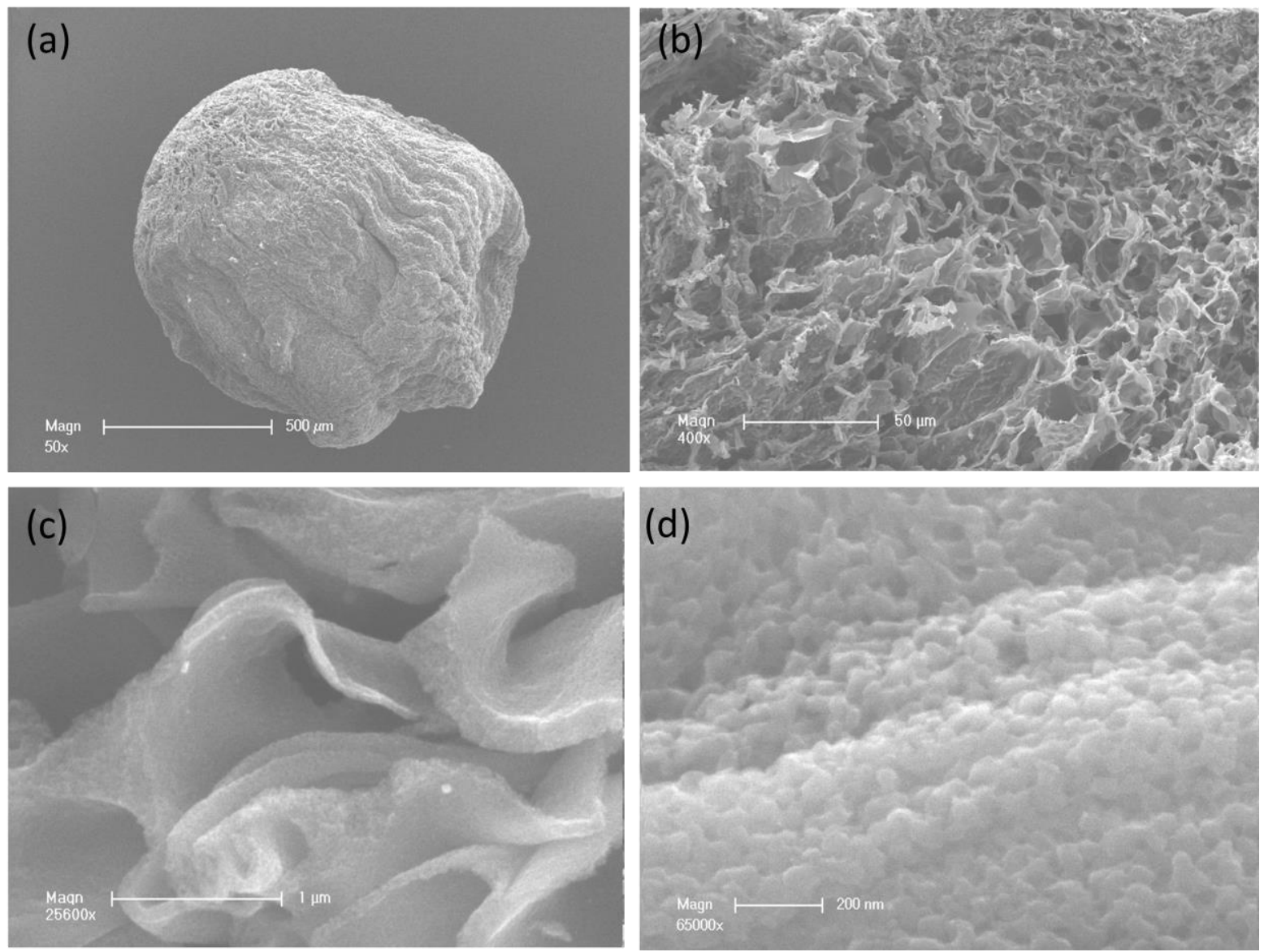

Figure 5: SEM pictures of BC-B carbon beads at different magnifications. (a) General view of a carbonized bead. (b-d) The interior of a bead at different magnification.

The higher magnification of SEM picture reveals the nanoscale corrugation of macropores walls (Fig. 5d). This is the sign of the nanoporosity of the material, which is clearly seen on the TEM images (Fig. 6) and which is induced to by the template removal in course of carbonization. 

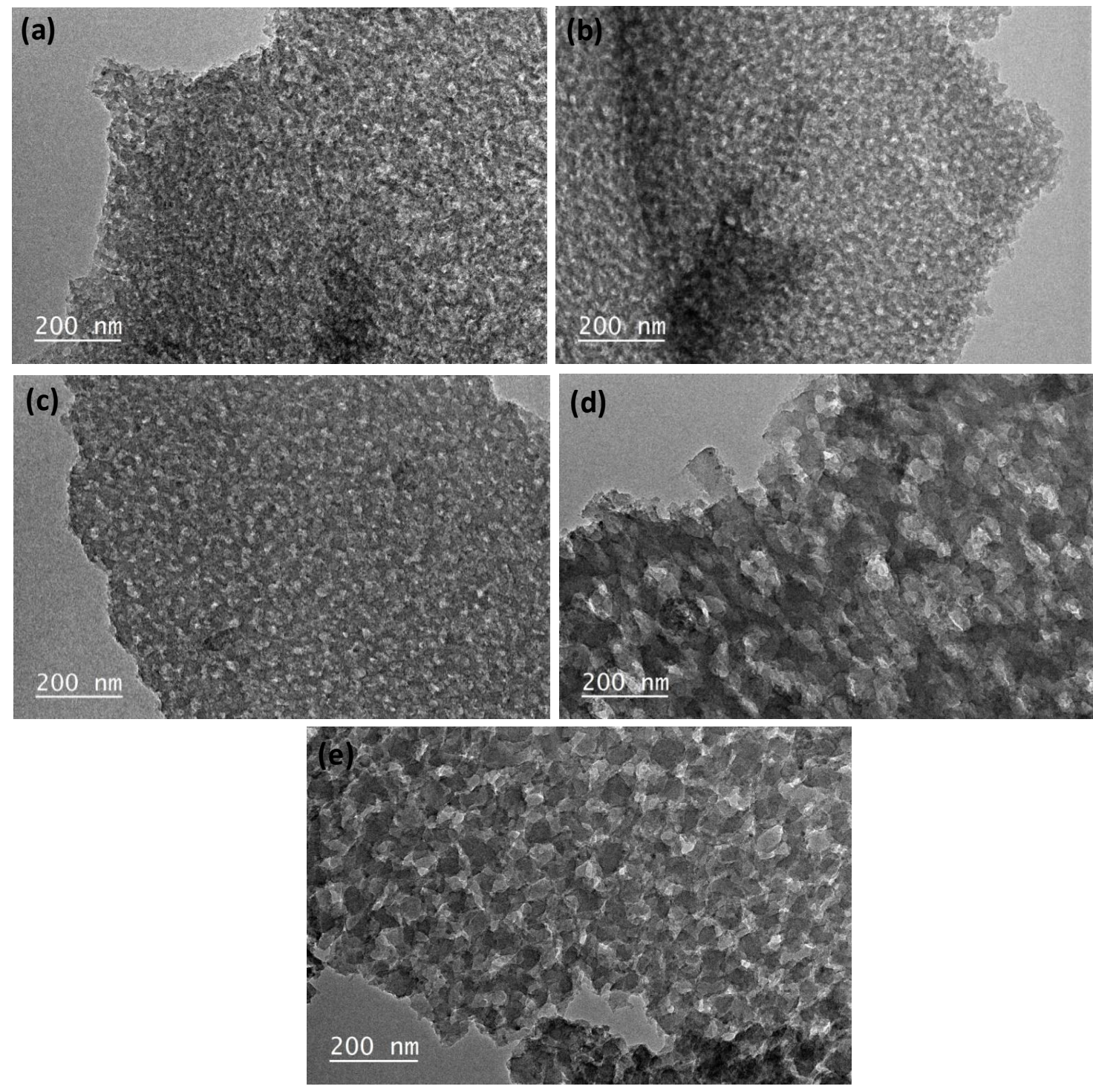

Figure 6: TEM pictures of carbon beads obtained with different experimental conditions (a)

CB-A (b) CB-B (c) CB-C (d) CB-D and (e) CB-E

Thus, the matrix of the beads can be considered at this hierarchy level as a mesoporous scaffold. Mesopores with uniform size distribution are clearly observed on all materials. For CB-A, CB-B and CB-C, the pore size is smaller than in the case of CB-D and CB-E, in good agreement with the tendency of pore size determined by nitrogen adsorption results (Fig.2b). 


\subsubsection{Beads surface morphology}

Freeze-drying of polymer solutions may result in the formation of a surface skin due to the collapse of the material at the solid-gas interface induced by the interfacial tension [49]. Freeze-drying and carbonization are accompanied also by shrinking of the beads. These two effects (surface skin formation and beads shrinking) give rise to an interesting micromechanical phenomenon in our experiments: formation of hierarchical wrinkled morphology on the surface of the beads (Fig. 7).

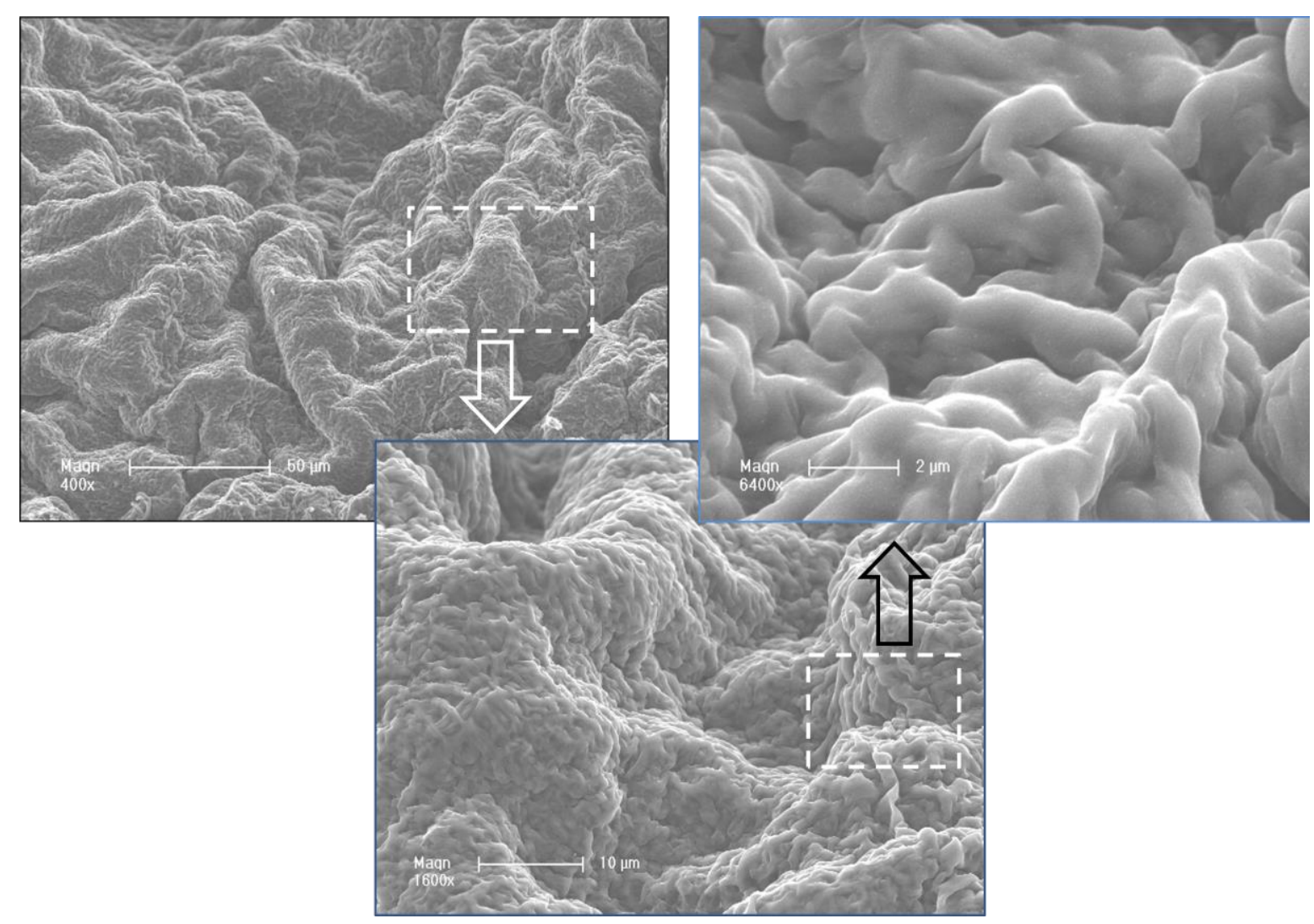

Figure 7: Hierarchical wrinkled structure of a BC-B-type bead.

Wrinkling of stiff solid films on soft substrates is a commonplace in nature and is often observed when the film and the substrate, bound to each other, have different equilibrium specific surface [53]. Efimenko et al. [54] have noticed recently that wrinkling can appear as a complex phenomenon, comprising the formation of hierarchical structure, with the short- 
periodical small amplitude wrinkles being «nested» in the wrinkles of much larger periodicity and amplitude. In their model, the initial small wrinkles form, after reaching certain critical amplitude, an effective skin layer of larger thickness. Further strain relaxation in the system (caused, for instance, by the substrate shrinking) leads to the wrinkling of this secondary skin, and so on. In our study, the wrinkles are very irregular, but one can clearly identify two generations. For the beads CB-B and CB-C, the wrinkles of the two generations have the characteristiclengths of 2 and $50 \mu \mathrm{m}$, approximately (see Supporting Information, Figure S5). It should be noted that the beads CB-A and CB-D are characterized by a single generation of highly irregular wrinkles, having approximate length order of $10 \mu \mathrm{m}$ (see Supporting Information, Figure S5).

\subsection{Structural characterization}

Figure 8a shows a survey scan spectrum of $\mathrm{BC}-\mathrm{B}$ carbon material, with the peaks of $\mathrm{C} 1 \mathrm{~s}, \mathrm{~N}$ $1 \mathrm{~s}$ and $\mathrm{O} 1 \mathrm{~s}$ positioned at 285,401 and $532 \mathrm{eV}$, respectively [55]. The material contains mainly carbon, oxygen, and nitrogen, without any other impurities detected. The composition of all materials is provided in Table 2. We may notice that the nitrogen amount is comprised between 3.4 and 6.4 at\%. The lowest nitrogen amount is determined for CB-C while the highest one for CB-A. To recall, these materials were prepared with the same amount of chitosan solution and template while they contain either the highest amount of cross-linker (CB-C) or no cross-linker (CB-A). Therefore, the cross linker influences the composition of the obtained carbon beads. This can be understood by the cross-linking of chitosan with glyoxal inducing the formation of polymer resin giving carbon bead with richer carbon content and in the same time lower nitrogen contribution. 

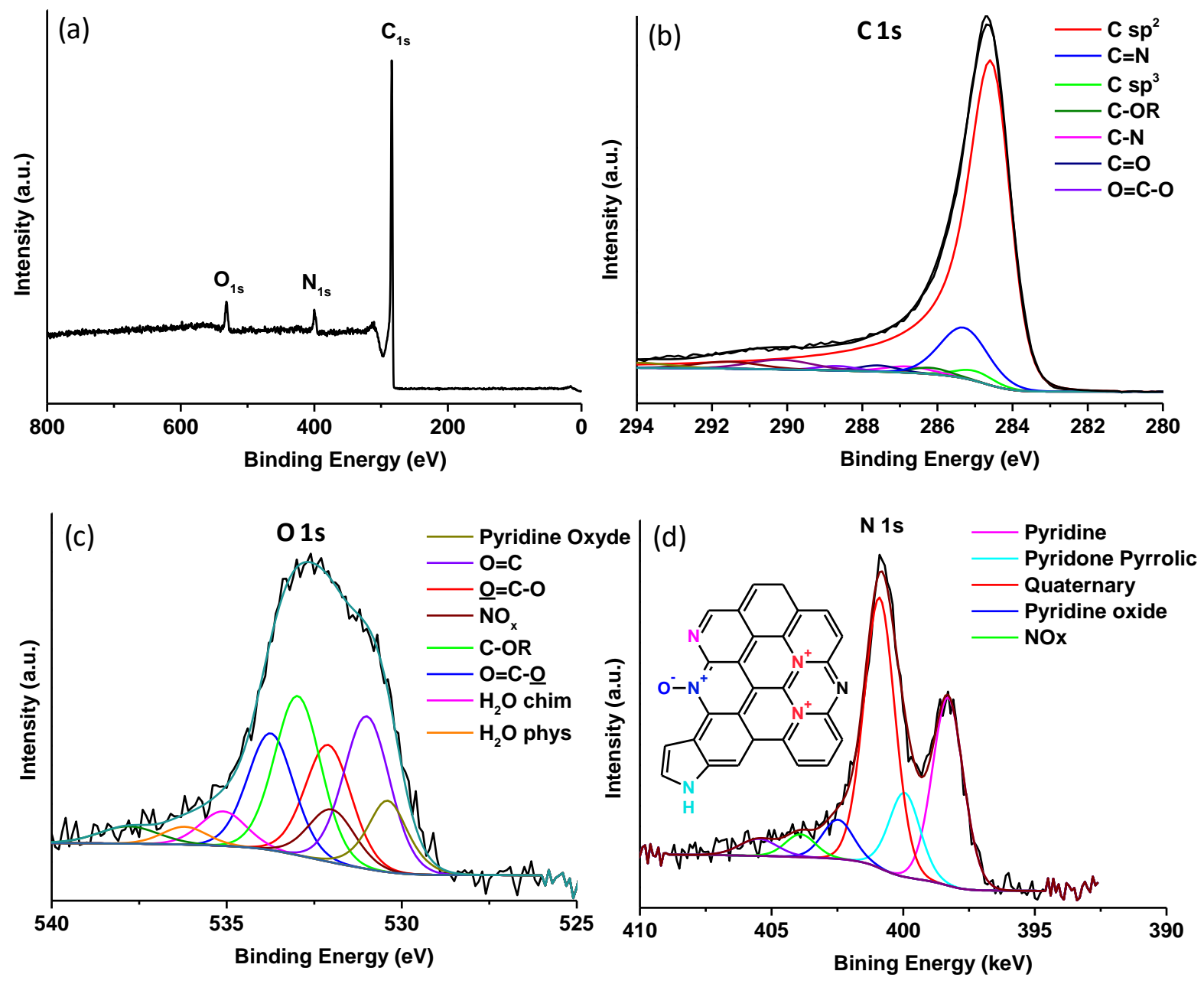

Figure 8: XPS spectra of CB-B (a) survey spectra and high resolution spectra (b) C1s, (c) O1s and (d) N1s (in-set: representation of nitrogen groups in the carbon framework).

The high-resolution C1s XPS spectra (Figure 8b) present the most intense peak at $284.5 \mathrm{eV}$ which is assigned to graphite-like $\mathrm{sp}^{2}$ carbon [56]. A tail of asymmetric C1s peak at higher binding energies is originated from the presence of carbon atoms bonded to nitrogen $(\mathrm{C}=\mathrm{N}$ and $\mathrm{C}-\mathrm{N})$ and different oxygen-functional groups $(\mathrm{C}-\mathrm{OR}, \mathrm{C}=\mathrm{O}$ and $\mathrm{O}=\mathrm{C}-\mathrm{O})$. These groups are well visible in the O1s peak (Figure 8c) and are formed due to the decomposition of chitosan and cross-linker.

Figure 8d shows the high-resolution N1s XPS spectra which was deconvoluted into five main component peaks i.e., pyridinic nitrogen $(398 \mathrm{eV})$, pyrrolic nitrogen $(400 \mathrm{eV})$, quaternary nitrogen $(401 \mathrm{eV})$, pyridine oxide $(403 \mathrm{eV})$ and nitrogen oxides $(404 \mathrm{eV})$. 
In pyridinic nitrogen structure, the $\mathrm{N}$ atom is $\mathrm{sp} 2$ hybridized with two $\mathrm{C}$ atoms, while in the quaternary structure one $\mathrm{C}$ atom is substituted by an $\mathrm{N}$ atom in the graphitic structure. The pyrrolic nitrogen is sp3 hybridized in a five-member ring (in-set Figure 8d). The quaternary and pyridine are present in greater quantities compared to the other groups.

\subsection{Chitosan beads structure and transformation into carbon}

The structure of chitosan based spheres prepared in the absence of cross-linker and in the presence of glyoxal and glyoxylic acid cross-linkers was evaluated by ${ }^{13} \mathrm{C}$ NMR (Figure 9a). For comparison purpose the chitosan raw material was analyzed as well. The spectra of chitosan show several signals at 175, 105, 83, 76, 61, 58 and $24 \mathrm{ppm}$. The signals from 175 ppm and $25 \mathrm{ppm}$ correspond to the carbonyl carbon and the methyl carbon of $-\mathrm{COCH}_{3}$ group. The peak at 105 ppm is related to carbon $\mathrm{C} 1$ bonded with hydrogen chitosan and the signals at $58 \mathrm{ppm}(\mathrm{C} 2), 61 \mathrm{ppm}(\mathrm{C} 6), 76 \mathrm{ppm}(\mathrm{C} 3-\mathrm{C} 5)$ and $83 \mathrm{ppm}(\mathrm{C} 4)$ are assigned to different carbons of glucosamine ring [57;58] (in-set Figure 9a).

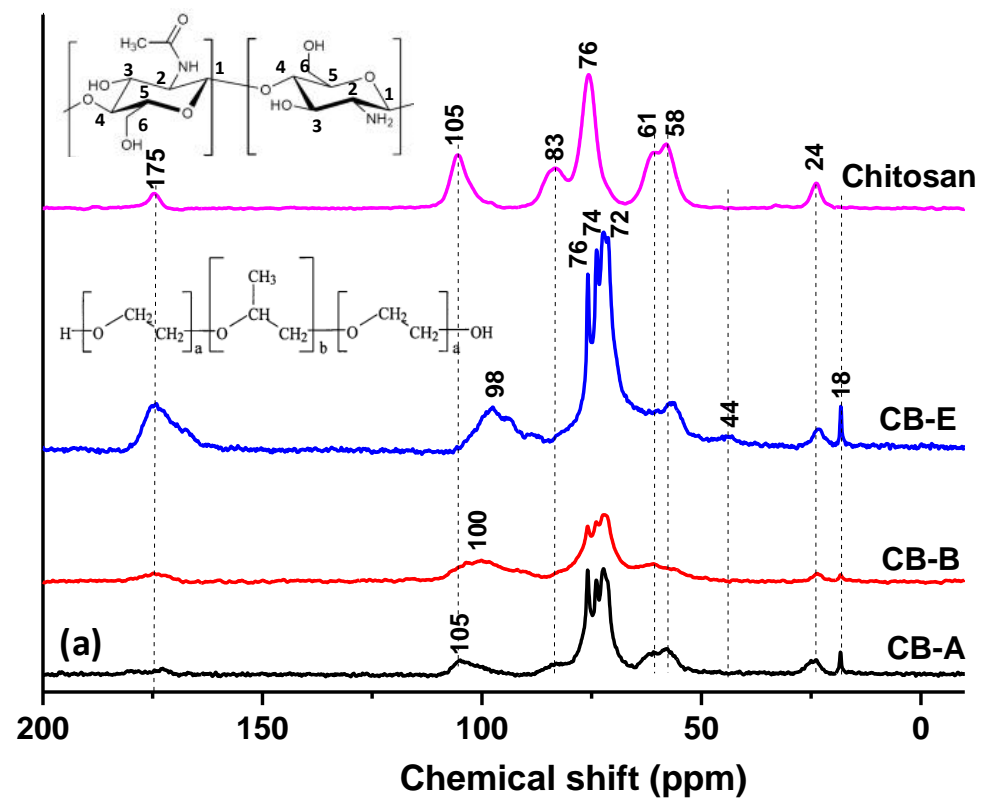




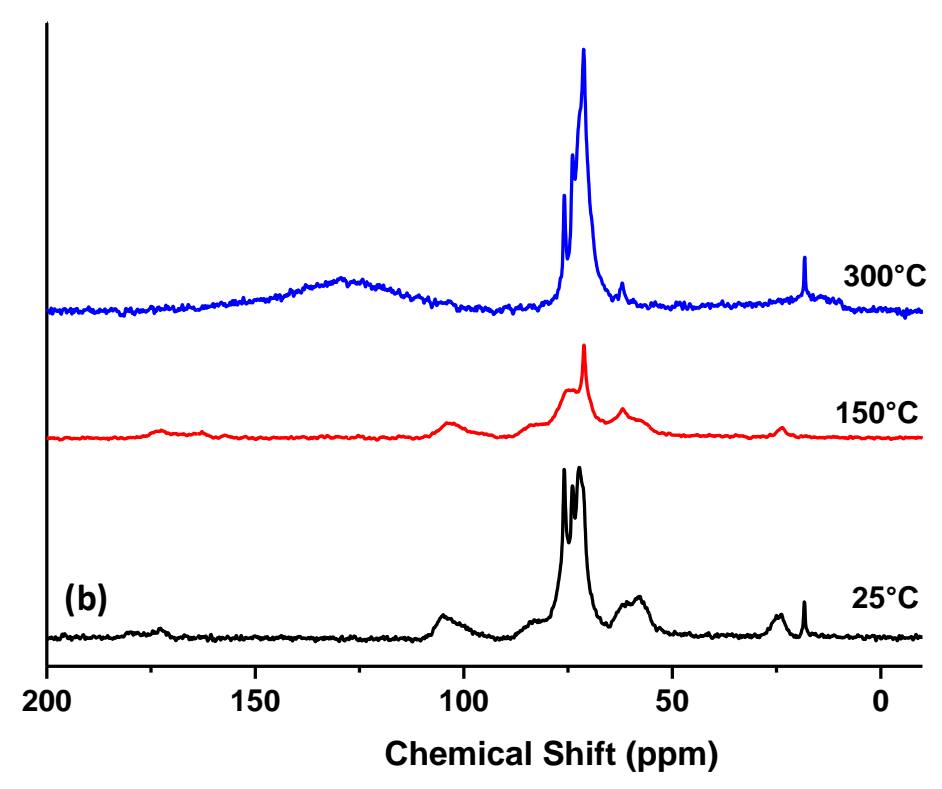

Figure 9: ${ }^{13} \mathrm{C}$ CP-MAS solid state NMR spectra of (a) chitosan beads prepared with or without cross-linkers: CB-A (no cross-linker), CB-B (glyoxal cross-linker), CB-E (Glyoxylic acid cross-linker) and chitosan precursor (in-set: chitosan and Pluronic F-127 chemical formula) and (b) chitosan beads $\mathrm{CB}-\mathrm{A}$ (no cross-linker) prepared at $25^{\circ} \mathrm{C}$ and further heated at $150^{\circ} \mathrm{C}$ and $300^{\circ} \mathrm{C}$<smiles>NC1C(O)C(O)OC(COC(OCC2OC(O)C(O)C(N)C2O)C(OCC2OC(O)C(O)C(N)C2O)OCC2OC(O)C(N)C(O)C2O)C1O</smiles><smiles>O=C(O)CNC1C(O)OC(CO)C(O)C1O</smiles>

(B)

Figure 10: Schematically representation cross-linking products (a) between the $-\mathrm{OH}$ of glucosamine and aldehyde group of glyoxal or glyoxylic acid and (b) between the $-\mathrm{NH}_{2}$ group of glucosamine and aldehyde group of glyoxylic acid. 
When pluronic template is added to the chitosan solution to form the CB-A (absence of crosslinker), most of the chitosan peaks are visible. Changes in the NMR spectra are clearly seen at around $76 \mathrm{ppm}$ and a new peak at $18 \mathrm{ppm}$ appears. The peak at $\sim 76 \mathrm{ppm}$ can be attributed to the carbon atoms bonded with $\mathrm{O}$ atoms in the PEO moieties of Pluronic F-127 template $\left(\mathrm{CH}_{2}-\right.$ $\mathrm{O}-\mathrm{CH}_{2}$ ) while the peaks from 74, $72 \mathrm{ppm}$ and from $18 \mathrm{ppm}$ are assigned to the carbons involved in ethyl $\left(-\mathrm{CH}-\mathrm{CH}_{2}\right)$ and methyl $\left(-\mathrm{CH}_{3}\right)$ groups, respectively, of the PPO moieties of Pluronic F-127 template (in-set Figure 9) [40;46].

When the glyoxal and glyoxylic acid cross-linkers are used (CB-B and CB-E) in addition, we notice a significant shift of the 105ppm peak (C1) to lower values (98-100 ppm). Moreover, the signal from $83 \mathrm{ppm}(\mathrm{C} 4)$ is no longer visible. This can be related to the carbon atoms involved in glyoxal (glyoxylic acid) which have been reacted with the chitosan. The $-\mathrm{OH}$ groups of glucosamine reacts with the carbonyl group of glyoxal forming the compound described in Figure 10a which have the NMR position placed at $101 \mathrm{ppm}$. This indicates the cross-linking of chitosan with the glyoxal/glyoxylic acid [59].

The modification or cross-linking of chitosan with aldehydes is a very important issue to design chitosan materials with improved mechanical properties and resistance in extreme media conditions or to enhance the performances as adsorbent for metal ions, dyes, pharmaceutical compounds removal from water etc. [60] Therefore, the modification of chitosan with aldehydes less toxic than formaldehyde maybe of great importance particularly in biomedical and environmental applications.

For chitosan beads prepared with glyoxylic acid, the peak at $175 \mathrm{ppm}$ become very broad and a supplementary small peak appear at $44 \mathrm{ppm}$. These peaks could be assigned to carbons involved in $\mathrm{C}=\mathrm{O}$ group substituted on $-\mathrm{NH}$ and respectively to carbons bonded to $\mathrm{NH}$ and $\mathrm{COOH}$ groups $[59 ; 61]$ as schematically represented in Figure 10b. Thus, the amino group of glucosamine reacted with the aldehyde group of glyoxylic acid to form aminoacid groups. 
The structure of chitosan spheres thermally treated at $25^{\circ} \mathrm{C}, 150^{\circ} \mathrm{C}$ and $300^{\circ} \mathrm{C}$, was evaluated also by ${ }^{13} \mathrm{C}$ NMR (Figure 9b). By increasing the temperature at $150^{\circ} \mathrm{C}$, the chitosan peaks become less pronounced and they disappear at $300^{\circ} \mathrm{C}$ in the favor of a large peak at around $120 \mathrm{ppm}$ characteristics to polyaromatic carbons. This is an indication of carbonization of chitosan at $300^{\circ} \mathrm{C}$. The pluronic F-127 peak can be observed at $150^{\circ} \mathrm{C}$ and $300^{\circ} \mathrm{C}$ but a decrease in the intensity of the $76 \mathrm{ppm}$ peak related to the hydrophilic PPO part of the template is noticed.

Further insight in the thermal decomposition of chitosan beads was assessed by thermogravimetric analysis. The thermal decomposition behavior of the individual precursors employed for the preparations of the chitosan beads and the resulting chitosan resin beads were studied (Figure 11). Chitosan present a decomposition peak at $\sim 300^{\circ} \mathrm{C}$ and a high carbon yield $(\sim 40 \mathrm{wt} . \%)$ is remaining at $600^{\circ} \mathrm{C}$ (Figure 11a). This is in line with the NMR results showing the carbonization of chitosan at such temperature. Glyoxal cross-linker exhibit two peaks placed at $\sim 100^{\circ} \mathrm{C}$ corresponding to the water loss, and a second peak at $200^{\circ} \mathrm{C}$ related to the decomposition of glyoxal. For glyoxylic acid only one peak at around $200^{\circ} \mathrm{C}$ is observed while the pluronic template decomposes at around $375^{\circ} \mathrm{C}$ with no residue left at $600^{\circ} \mathrm{C}$ as is the case of cross-linker as well (Figure 11a).

The chitosan beads show mainly a principal decomposition peak at $375^{\circ} \mathrm{C}$ (Figure $11 \mathrm{~b}$ ) which is related with the decomposition of the template, the other peaks corresponding to chitosan and cross-linker are only slightly visible. The carbon yield varies from 15 to 40 wt.\% depending on the amount of chitosan reported to the other precursors, higher the chitosan quantity inducing better carbon yields. 

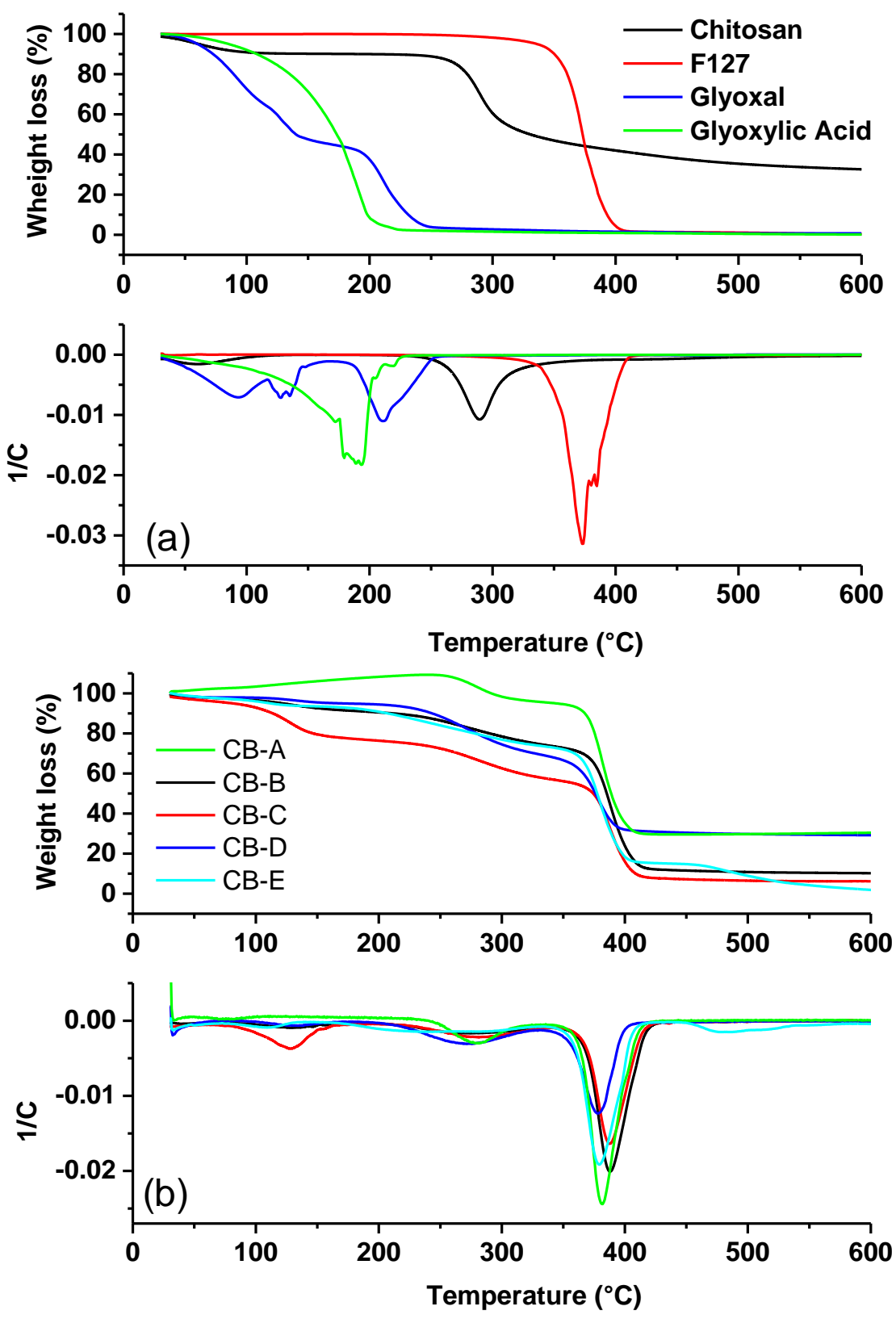

Figure 11: (a) TGA under nitrogen of (a) individual precursors and (b) chitosan beads obtained using different experimental conditions.

Therefore, the prepared carbon beads are characterized by several levels of structural organization: the spherical beads ( $\mathrm{mm}$ size), the macropore-scale (micron size), and the nanopores (micro/mesopores, 0.5 to $50 \mathrm{~nm}$ ). Each of the organization levels is achieved via a corresponding physical/chemical process.

Firstly, the carbon beads are uniform in shape and formed by dropping solutions of chitosan 
acetate in liquid nitrogen (LN). Their surface morphology is formed by a rigid skin which present wrinkles with well-defined structure.

Secondly, the macropores result from the water crystal growth in the beads at the contact with the LN followed by freeze-drying of the beads. The $\mathrm{Hg}$ intrusion measurements revealed the important volume of macropores. Particularly, for CB-D and CB-E, this volume is significantly higher than for the other materials (Table 2), however, it is not clear yet how the chemical composition of chitosan particles influences the macroporosity since no trend could be established.

The last, the micro/mesopores appear due to pyrolysis of the chitosan beads, i.e., the micropores are derived by the decomposition chitosan resin polymer while the elimination of the template molecules allowed the formation of mesopores. The microporous volume and implicitly the surface area are rather similar for all samples except CB-C which exhibit lower values. This maybe linked to the higher amounts of glyoxal cross-linker used to prepare this material. As for the mesopore formation, a necessary condition is the use of the pluronic template, as demonstrate by the reference carbon material (CB-R) prepared without template which showed the absence of mesopores but the presence of both -micro and -macro pores. In the presence of the template (CB-A to CB-E materials), the mesopores are formed and their size/volume depend on one hand on the amount of template, i.e., higher amounts of template favoring higher pore volume but similar pore size. On the other hand, for the same amount of template, the cross-linker amount and type have also an influence on the pore size/volume. A high amount of glyoxal cross-linker (CB-C, Table 2) decreases the mesopore volume but keeps the same pore size as $\mathrm{CB}-\mathrm{A}$ and $\mathrm{CB}-\mathrm{B}$, while the type of cross-linker influence both the pore size and pore volume (CB-B-glyoxal vs. CB-E-glyoxylic acid). The different mechanism of cross-linking between the glyoxal and glyoxylic acid with chitosan results in different chitosan resins as showed by NMR results. Such resin is able to self-assemble with Pluronic 
F-127 template through $\mathrm{H}$-bonding interactions, explaining the distinct textural properties (pore size/pore volume) of carbon derived beads. It is worth to note that in the absence of cross-linker, chitosan is still able to assemble with the template giving hierarchical porous beads as well (CB-A). Therefore, the cross-linker is not required to form the -micro or -meso porosity but rather to tune it. In addition, the composition of carbon beads $(\mathrm{C}, \mathrm{N}, \mathrm{O})$ is also modified in the presence of cross-linker (XPS results) due to their ability to form resins with different chemical compositions. Therefore, tuning the cross-linkers and the template type/amount allow to design hierarchical nitrogen doped carbons with various morphology, texture and composition.

\section{Conclusion}

In summary, we have developed an eco-friendly procedure for the fabrication of nitrogendoped carbonized beads with hierarchical morphology of the pores. The beads are produced by chitosan acetate, cross-linkers and Pluronic F127 co-solution drops in liquid nitrogen, freeze drying and carbonization. The macropores are generated by phase separation caused by the growth of water ice microcrystals in the drops. The nanoscale pores (micro and mesopores) are formed by the decomposition of chitosan resin/ template assemblies during the carbonization step and the pore sizes and volumes could be varied tuned with glyoxal and glyoxylic acid cross-linkers exhibiting different mechanisms of reaction with chitosan as highlighted by ${ }^{13} \mathrm{C}$ NMR. The carbon bead composition $(\mathrm{C}, \mathrm{N}, \mathrm{O})$ was found to be related to the chitosan resin composition. A relatively rigid "skin" layer is formed on the surface of the beads in course of freeze-drying. Unequal contraction of the inner parts of the beads and their surface leads to the surface wrinkling. The fact that the beads are produced from readily available, renewable bioresource precursors in aqueous solution make this approach especially attractive for the numerous applications where controlled pore size at different 
levels is required. Submillimeter dimensions and almost spherical form of the carbonized beads make them a convenient granular material, which is capable to take the shape of various recipients and can be easily recovered from the reaction medium.

\section{Acknowledgements}

The authors thank Dr. Loic Vidal for performing TEM analysis, Gauthier Schrodj for TGA analysis, Stephan Knopf for SEM, Luc Delmotte for ${ }^{13}$ C NMR, Samar Hajjar for XPS and Habiba Nouali for $\mathrm{Hg}$ intrusion measurements. The technical characterization analyses were performed in the frame of the IS2M technical platforms.

\section{References}

[1] Primo A, Atienzar P, Sanchez E, Delgado J, Garcia H, Chem Commun, 48 (2012) 92546.

[2] Prabhu C, Valechha A, Wanjari S, Labhsetwar N, Kotwal S, Satyanarayanan T, Rayalu S, J Molecular Catalys B, 71 (2011) 71-8.

[3] Fujiki J, and Yogo K, Chem Commun, 4 (2016) 186-9.

[4] Wrobel-Iwaniek I, Diez N, Gryglewicz G, Int .J.Hydrogen Eneergy, 40 (2015) 5788-96.

[5] Sliwak A, Diez N, Miniach E, Gryglewicz G, J Appl Electrochem, 46 (2016) 667-77.

[6] Sun G, Li.B, Ran J, Shen X, Tong H, Electrochimica Acta, 171 (2015) 13-22.

[7] Hao P, Zhao Z, Leng Y, Tian J, Sang Y, Boughton R, Wong C, Liu H, Yang B, NanoEnergy, 2015 (2015) 9-23.

[8] Deng X, Zhao B, Zhu L, Shao Z, Carbon, 93 (2015) 48-58.

[9] Chen C, Zhao C, Hu Z, Liu K, Funct Mater Lett, 10 (2017) 1650074.

[10] Ling Z, Yu C, Fan X, Liu S, Yang J, Zhang M, Wang G, Xiao N, Qiu J, Nanotechnology, 26 (2015) 374003-14.

[11] Chen X, Wang W, Songand Z, Wang J, Anal Methods, 3 (2011) 1769-73.

[12] Baek S-H, Kim B, Suh K-D, Colloids and Surfaces A, 316 (2008) 292-6.

[13] Prashanth K, and Tharanathan R, Trends Food Sci Technology, 18 (2007) 117-31. 
[14] Cauchie H, Hydrobiologia, 470 (2002) 63-96.

[15] Wu T, Wang G, Zhang X, Chen C, Zhang Y, Zhao H, Chem Commun, 51 (2015) 13347.

[16] Xing T, Zheng Y, Li L, Cowies B, Gunzelmann D, Qiao S, Huang S, Chen Y, ASC Nano, 8 (2014) 6856-62.

[17] Guo D, Shibuya R, Akiba C, Saji S, Kondo T, Nakamura J, Science, 351 (2009) 361-5.

[18] Chen L, Zhang X, Liang H, Kong M, Guan Q, Chen P, Wu Z, Yu S, ACS Nano, 6 (2012) 7092-102.

[19] Dutta S, Bhaumik A, K C-W Wu, Energ.Environ.Sci., 7 (2014) 3574-92.

[20] Builes S, Roussel T, Matei Ghimbeu C, Parmentier J, Gadiou R, Vix-Guterl C, Vega L, Phys.Chem.Chem.Phys., 13 (2011) 16063-70.

[21] Chmiola J, Yushin G, Gogotsi Y, Portet C, Simon P, Taberna P, Science, 313 (2006) 1760-3.

[22] Decaux C, Matei-Ghimbeu C, Dahbi M, Anouti M, Lemordant D, Beguin F, Vix-Guterl C, Raymundo-Piñero E, J.Power Sources, 263 (2014) 130-40.

[23] Kim M-H, Kim K-B, Park S-M, Roth K, Scientific Reports, 6 (2016) 21182.

[24] Liu Y, Feng Y, Yao J, RSC Adv., 6 (2016) 80840-6.

[25] Qi J, Li J, Fang X, Sun X, Shen J, Han W, Wang L, Chem Eng J, 307 (2017) 989-98.

[26] Yamamoto T, Endo A, Eiadua A, Ohmori T, Nakaiawa M, Soottitantawat A, Mater Inter Electrochem Phenom, 53 (2007) 746-9.

[27] Khare P, Sharma A, Verma N, J Colloid Interf.Sci., 418 (2014) 216-24.

[28] Wang Z, Li F, Stein A, Nano Lett., 7 (2007) 3223-6.

[29] Marquez-Nieto A, Romero R, Romero A, Valverde J, J Mater Chem, 21 (2010) 166472.

[30] Liu J, Qiao S, Liu H, Chen J, Orpe A, Zhao D, Lu GQ, Angew.Chem.Int.Ed., 50 (2011) 5947-51.

[31] Kim TW, Chung PW, Slowing II, Tsunoda M, Yeung ES, Lin VSY, Nano Lett., 8 (2008) 3724-7.

[32] Shinha V, Singla A, Wadhawan S, Kaushik R, Kumria R, Bansal K, Dhawan S, Int.J Pharm, 274 (2004) 1-33.

[33] Peniche C, Monal-Arguelles W, Peniche H, Acosta N, Macromol Biosci, 3 (2003) 511 20.

[34] Chuenchom L, Kraehnert R, Smarsly BM, Soft Matter, 8 (2012) 10801-12. 
[35] Liang C, Li Z, Dai S, Angew.Chem.Int.Ed., 47 (2008) 3696-717.

[36] Ma T-Y, Liu L, Yuan Z-Y, Chem.Soc.Rev., 42 (2013) 3977-4003.

[37] Ndamanisha JC, and Guo LP, Anal.Chim.Acta, 747 (2012) 19-28.

[38] Fechler N, Fellinger T-P, Antonietti M, Adv.Mater., 25 (2013) 75-9.

[39] Masika E, and Mokaya R, RSC Advances, 3 (2013) 17677-81.

[40] Nita C, Bensafia M, Vaulot C, Delmotte L, Matei Ghimbeu C, Carbon, 109 (2016) 227 38.

[41] Olejniczak A, Lezanska M, Wloch J, Kucinska K, Lukaszewicz J, J Mater Chem, 1 (2013) 8961-7.

[42] Rammonhan A, Tayal L, Kumar A, Sivakumar S, Sharma A, RSC Advances, 3 (2013) 2008-16.

[43] Meng Y, Gu D, Zhang F, Shi Y, Yang H, Li Z, Yu C, Tu B, Zhao D, Angew.Chem.Int.Ed., 117 (2005) 7215-21.

[44] Matei Ghimbeu C, Le Meins J, Zlotea C, Vidal L, Schrodj G, Latroche M, Vix-Guterl C, Carbon, 67 (2014) 260-72.

[45] Mayes RT, Tsouris C, Kiggangs Jr. JO, Mahurin SM, DePaoli DW, Dai S, J.Mater.Chem., 20 (2010) 8674-8.

[46] Matei Ghimbeu C, Vidal L, Delmotte L, Le Meins J-M, Vix-Guterl C, Green Chemistry, 16 (2014) 3079-88.

[47] Washburn E, Phys Rev, 17 (1921) 273-83.

[48] Matei Ghimbeu C, Puscasu A, Martinez de Yuso A, Zlotea C, Oumellal Y, Latroche M, Vix-Guterl C, Micro.Mesoporous.Mater., 223 (2016) 79-88.

[49] Ho M-H, Kuo P-Y, Hsieh H-J, Hsien T-Y, Hou L-T, Lai J-Y, Wang D-M, Biomaterials, 25 (2004) 129-38.

[50] Stokols S, and Tuszynski M, Biomaterials, 27 (2006) 443-51.

[51] Stokols S, and Tuszynski M, Biomaterials, 25 (2004) 5839-46.

[52] Wu X, Black L, Santacana-Laffitte C, Patrick C, J Biomed Mater Res Part A, 81 (2007) 59-65.

[53] Genzer J, and Groenewold J, Soft Matter, 2 (2006) 310-23.

[54] Efimenko K, Rackaitis M, Manias E, Vaziri A, Mahadevan L, Genzer J, Nat Mater, 4 (2005) 293-7.

[55] van Dommele S, Romero-Izquirdo A, Brydson R, de Jong K, Bitter J, Carbon, 1 (2008) 138-48. 
[56] Brender P, Gadiou R, Rietsch JC, Fioux P, Dentzer J, Ponche A, Vix-Guterl C, Anal.Chem., 84 (2012) 2147-53.

[57] Taboada E, Cabrera G, Cardenas G, Appl Polymer Sci, 91 (2004) 807-12.

[58] Heux L, Brugnerotto J, Desbrieres J, Versali M, Rinaudo M, Biomacromolecules, 1 (2000) 746-51.

[59] Yang Q, Dou F, Liang B, Shen Q, Carbohydrate Polymers, 59 (2005) 205-10.

[60] Kyzas G, and Bikiaris D, Marine Drugs, 13 (2015) 312-37.

[61] Mourya V, Inamdar NN, Tiwari A, Adv Mater Lett, 1 (2010) 11-33. 